\title{
Povidone Iodine vs Tetracycline Fibers- To Analyse the Therapeutic Effect
}

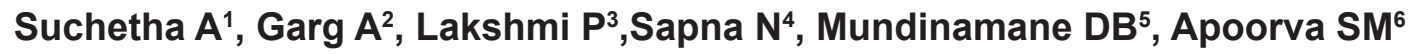

\begin{abstract}
Aim: This study was designed to compare the efficacy of tetracycline fibres and povidone iodine when locally delivered to the moderately deep periodontal pocket.

Materials and methods: 30 subjects were selected for the study and divided into two groups; Group I received Tetracycline fibers (Periodontal AB Plus), Group II received Povidone iodine local drug delivery. The Gingival Index (GI), Probing Pocket Depth (PPD) and Clinical Attachment Level (CAL) were measured at baseline and at 3 months.

Results: The intragroup comparison between PPD, CAL and GI at baseline and 3 months showed a statistically significant difference in group I in relation to all parameters; in group II, the PPD and CAL did not show a statistically significant difference. The intergroup comparison of PPD and CAL at the end of 3 months, showed a statistically significant difference between the two groups, with tetracycline fibers giving superior results.
\end{abstract}

Conclusion: Tetracycline fibers were more efficacious in improving the periodontal health status when compared to Povidone Iodine.

Keywords: Tetracycline Fibers, Povidone iodine, Local Drug Delivery, Probing pocket depth, Clinical attachment level

${ }^{1}$ Professor and Head

Department of Periodontics

D A P M R V Dental College, Bangalore,

Karnataka (INDIA)

2 Post Graduate Student Department of Periodontics

D A P M R V Dental College, Bangalore,

Karnataka (INDIA)

${ }^{3}$ Post Graduate Student

Department of Periodontics

D A P M R V Dental College, Bangalore,

Karnataka (INDIA)

${ }^{4}$ Reader

Department of Periodontics

D A P M R V Dental College, Bangalore,

Karnataka (INDIA)

${ }^{5}$ Reader

Department of Periodontics

DAPMRV Dental College, Bangalore, Karnataka (INDIA)

\section{Contact Author \\ Dr. Lakshmi P \\ lakshmi.p.menon83@gmail.com \\ J Oral Health Comm Dent 2014;8(1)24-29}

\section{INTRODUCTION}

$\mathrm{P}$ eriodontitis is characterized by a destruction of the periodontal ligament, a resorption of the alveolar bone and the migration of the junctional epithelium along the tooth surface. The clinical signs of periodontitis are changes in the morphology of gingival tissues, bleeding upon probing as well as periodontal pocket formation. This pocket provides an ideal environment for the growth and proliferation of anaerobic pathogenic bacteria (1). Microorganisms colonizing the subgingival area represent the principal etiological factor in the development of the inflammation and tissue destruction. The microflora found in periodontitis is complex and composed mainly of gram negative anaerobic bacteria (2).

Current periodontal therapy aims at removing bacterial deposits from the tooth surface so as to achieve periodontal health. Scaling and root planing, in combination with optimal oral hygiene, has been shown to stop periodontal destruction in many cases (3). However, severe or aggressive forms of periodontitis in young subjects as well as patients or sites which are refractory to treatment often cannot be arrested by mechanical treatment alone. In such situations antimicrobial agents are of great interest and may be valuable as adjuncts to mechanical therapy (4).

Systemically applied antimicrobials have been advocated for the treatment of severe, aggressive or refractory forms of periodontitis. However, development of antibiotic resistance and other systemic side effects like gastrointestinal disturbances have been reported $(5,6)$. Moreover, the active product could not achieve an adequate concentration at the site of action and was not retained locally for a sufficient period of time. 
These drawbacks of systemic administration of antimicrobial agent can be largely overcome by the use of local drug delivery of antimicrobial agents. Sustained local delivery systems might also be recommended for sites considered as difficult to instrument because of depth or anatomical complexity $(7,8)$.

A few studies have evaluated the effects of local drug delivery systems on sites that responded poorly or showed recurrence after scaling and root Planing (9).

Success of any drug delivery system designed to target periodontal infections depend upon its ability to deliver the antimicrobial agents to the base of the pocket and to facilitate the retention of the medicament long enough to ensure an efficacious result $(10,11)$.

Various studies have been done on the local drug delivery with Tetracycline fibers and on the effect of rinsing with povidone iodine during non-surgical periodontal therapy $(12,13)$. In view of this, the study was designed to compare the efficacy of tetracycline fibers and povidone iodine when locally delivered to the moderately deep periodontal pocket.

\section{MATERIALS AND METHODS Sources of Data}

Ethical clearance for the study was received from the Institutional Ethical Committee and Review Board, D.A.P.M.R.V. Dental College, Bangalore, India. The data was collected over a period of 6 months, spanning from December 2011 to May 2012, from subjects visiting the outpatient section of Department of Periodontics, DAPMRV Dental College, Bangalore, India. Written informed consent was obtained from all patients. Patients aged 20-65 years were included in the study and comprised of both sexes. Exclusion criteria included patients with systemic diseases such as thyroid disorders, cardiovascular disorder, smokers, pregnant and lactating women. Subjects with periodontal probing depth less than $4 \mathrm{~mm}$ and greater than $6 \mathrm{~mm}$ and those who had received antibiotics for treatment for periodontal disease in the 3 months preceding the study were also excluded.

A total of 30 patients were selected and divided into 2 groups as follows:

\section{Group I}

Group I comprised of 15 patients with chronic periodontitis diagnosed clinically with presence of periodontal pockets and radiographically with bone loss. These patients were subjected to scaling and root planing and Local Drug Delivery therapy using Tetracycline Fibers (Periodontal AB Plus).

\section{GROUP II}

Group II comprised of 15 patients with chronic periodontitis diagnosed clinically with presence of periodontal pockets and radiographically with bone loss. These patients were subjected to scaling and root planing and Local Drug Delivery therapy using Povidone iodine.

\section{Parameters}

The parameters recorded for all the selected patients were:

- Gingival index (Loe and Sillness 1963) (GI)

- Probing pocket depth(PPD) using UNC 15 Probe

- Clinical Attachment Level(CAL)

\section{Site Selection}

Site with the deepest probing depth between $4 \mathrm{~mm}$ and $6 \mathrm{~mm}$ were chosen for the administration of the local drug delivery agent.

Technique to ascertain the Probing Pocket Depth (PPD) and Clinical attachment Level (CAL) at the experimental site:

A customized acrylic stent was fabricated for each patient for providing a reproducible insertion axis for the probe. The stent was grooved in an occlusal apical direction for the above mentioned purpose. The following clinical parameters were recorded to the nearest millimeter with the help of a UNC 15 probe. The following clinical parameters were measured for each experimental site before the procedure.

- Periodontal Probing Depth (PPD)

- Clinical Attachment Level (CAL)

Measurements were recorded from:

- Stent to cementoenamel junction (A)

- Stent to gingival margin (B)

- Stent to deepest probing depth at test sites (C)

- Calculation of the parameters

- Probing pocket depth $(\mathrm{PPD})=$ Stent to deepest probing depth

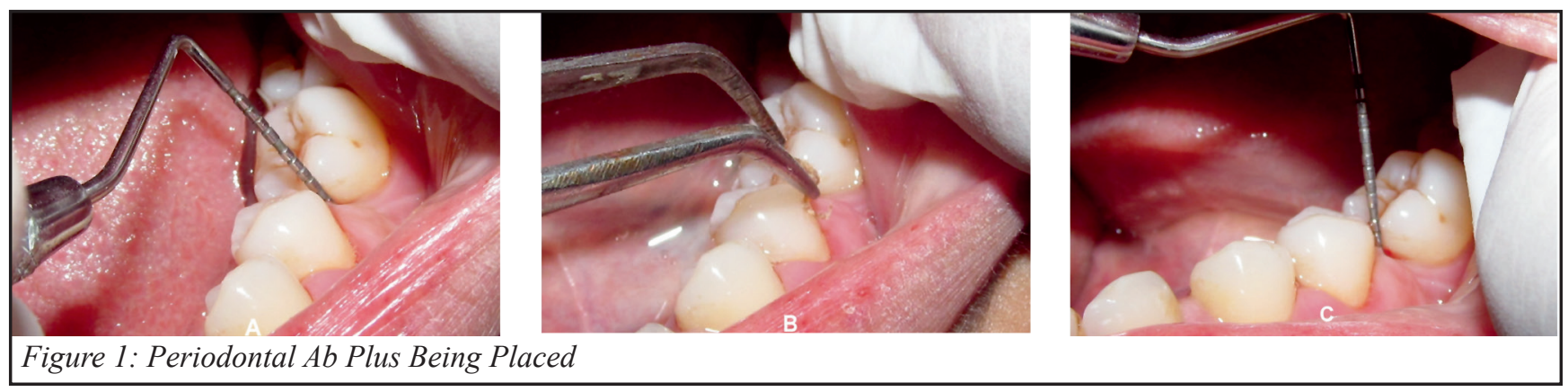




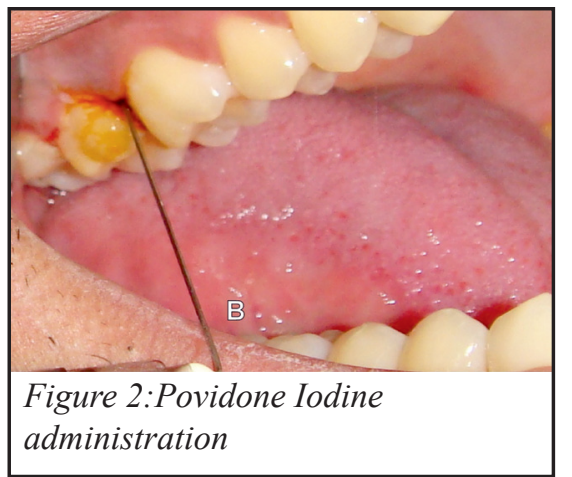

at test sites (C)- Stent to gingival margin (B)

- Clinical Attachment level $(\mathrm{CAL})=$ Stent to deepest probing depth at test sites (C)- Stent to cementoenamel junction (A)

\section{THE LOCAL DRUG DELIVERY Tetracycline fiber placement:}

Few drops of sterile saline solutions were added on fibers to wet it before placement. A small portion of the wet fibers was taken and placed at the prepared site and gently inserted into the pocket with periodontal probe. The gingiva was subsequently adapted to close the entrance of defect site (Figure 1).

\section{Povidone iodine administra- tion:}

Subgingival irrigation of the periodontal pockets in the selected site was performed with $5 \% \mathrm{v} / \mathrm{w}$ povidoneiodine solutions ( 3 irrigations with $1 \mathrm{ml}$ solution with interval 1 minute per periodontal pocket) (Figure 2).

The clinical parameters were reevaluated on day 90 . The data obtained was subjected to statistical analysis.

\section{STATISTICAL ANALYSIS}

The difference between the measurements (Probing pocket depth, Clinical attachment level, Gingival index) in the same individual was tested by paired ' $t$ ' test.

Unpaired t test was used to assess the difference between the groups with respect to Probing pocket depth(PPD), Clinical attachment level(CAL), and Gingival index(GI).

\section{RESULTS}

For each of the patients in the two groups, Probing pocket depth (PPD), Clinical attachment level(CAL) and gingival index(GI) were measured at baseline and at 3 months (90 days).

The intragroup analysis of PPD and CAL of the two groups are shown in Table 1. The intragroup comparison between PPD, CAL and GI at baseline and 3 months using paired $t$ test showed a statistically significant difference in group I in relation to all parameters, whereas in group II, the PPD and CAL did not show a statistically significant difference. The comparison of PPD, CAL, and GI of the two groups at baseline and at three months are given in Graph 1, Graph 2 and Graph 3 respectively.

The intergroup comparison of PPD and CAL at the end of 3 months using unpaired $t$ test showed a statistically significant difference between the two groups (Table 2).

There was no statistically significant difference in GI between the two groups at the end of 3 months (Table 3 ).

\section{DISCUSSION}

Several local drug delivery systems employed as monotherapies improved periodontal health and provided results that were not statistically significantly different than attained with scaling and root planing (SRP) alone. In contrast, many local drug delivery devices when used as adjuncts to SRP provided a statistically significant enhancement of parameters commonly used to monitor periodontal status.

The advantage of local drug delivery is that it reaches the base of periodontal pocket and is maintained for an ad-

\begin{tabular}{|c|c|c|c|c|c|c|c|c|}
\hline \multirow{2}{*}{$\begin{array}{l}\text { Study group } \\
\text { Baseline }\end{array}$} & \multicolumn{2}{|c|}{ Probing pocket depth(PPD) } & \multicolumn{2}{|c|}{$\begin{array}{l}\text { Clinical attachment } \\
\text { level (CAL) }\end{array}$} & \multicolumn{2}{|c|}{$\begin{array}{l}t \text { test (intragroup } \\
\text { comparison at baseline } \\
\text { and } 3 \text { months) }\end{array}$} & \multicolumn{2}{|l|}{ P value } \\
\hline & 3 months & Baseline & 3 months & PPD & CAL & PPD & CAL & \\
\hline $\begin{array}{l}\text { Group I } \\
\text { Group II }\end{array}$ & $5 \pm 0.756$ & $2.933 \pm 0.678$ & $\begin{array}{l}3.767 \pm 0.651 \\
3+0.598\end{array}$ & $1 \pm 0.802$ & 3.927 & 3.69 & $<0.001^{*}$ & $<0.001^{*}$ \\
\hline
\end{tabular}

\begin{tabular}{|c|c|c|c|c|c|c|c|}
\hline \multirow{2}{*}{$\begin{array}{l}\text { Study group } \\
\text { Baseline }\end{array}$} & \multicolumn{2}{|c|}{ Probing pocket depth(PPD) } & \multicolumn{2}{|c|}{$\begin{array}{l}\text { Clinical attachment } \\
\text { level (CAL) }\end{array}$} & \multicolumn{2}{|c|}{$\begin{array}{l}t \text { test (intragroup } \\
\text { comparison) }\end{array}$} & $P$ value \\
\hline & 3 months & Baseline & 3 months & PPD & CAL & PPD & CAL \\
\hline $\begin{array}{l}\text { Group I } \\
\text { Group II }\end{array}$ & $\begin{array}{l}5 \pm 0.756 \\
4.667 \pm 0.523\end{array}$ & $\begin{array}{l}2.933 \pm 0.678 \\
3.633 \pm 0.639\end{array}$ & $\begin{array}{l}3.767 \pm 0.651 \\
3 \pm 0.598\end{array}$ & $\begin{array}{l}1 \pm 0.802 \\
2.6 \pm 0.828\end{array}$ & 0.007 & 0.006 & $<0.05^{*}<0.05^{*}$ \\
\hline
\end{tabular}


Table 3: Comparison of gingival index (GI) in the two groups

\begin{tabular}{|c|c|c|c|c|c|}
\hline \multirow{2}{*}{$\begin{array}{l}\text { Study } \\
\text { group } \\
\text { comparison }\end{array}$} & \multicolumn{2}{|c|}{ Gingival index(GI) } & \multirow{2}{*}{$\begin{array}{l}\text { t test comparing } \\
\text { GI } \\
\text { index (intragroup) }\end{array}$} & \multirow{2}{*}{ p value } & \multirow{2}{*}{$\begin{array}{l}\text { Intergroup } \\
\text { (t test) }\end{array}$} \\
\hline & Baseline & 3 months & & & \\
\hline $\begin{array}{l}\text { Group I } \\
\text { Group II }\end{array}$ & $\begin{array}{l}2.32 \pm 0.414 \\
2.26 \pm 0.226\end{array}$ & $\begin{array}{l}1.2 \pm 0.2 \\
1.227 \pm 0.240\end{array}$ & $\begin{array}{l}5.286 \\
5.188\end{array}$ & $\begin{array}{l}<0.001^{*} \\
<0.001^{*}\end{array}$ & 0.744 \\
\hline
\end{tabular}

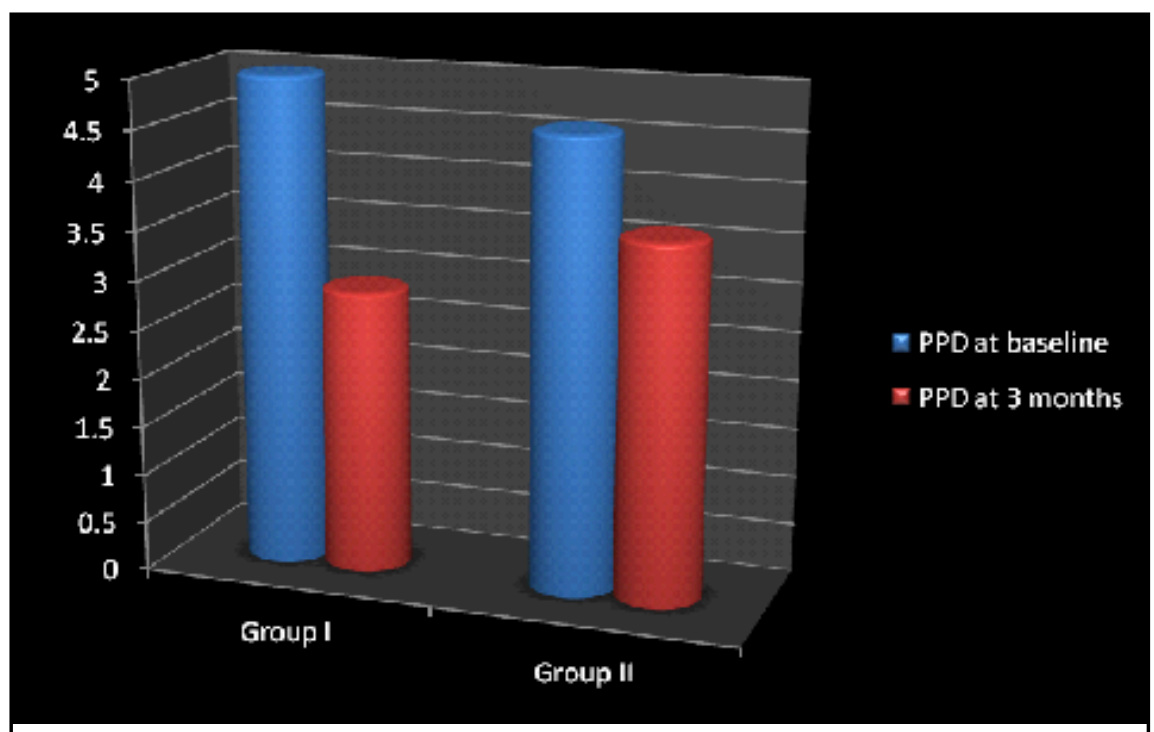

Figure 3: Comparison of Probing Pocket depth (PPD) in the 2 groups at baseline and 3 months

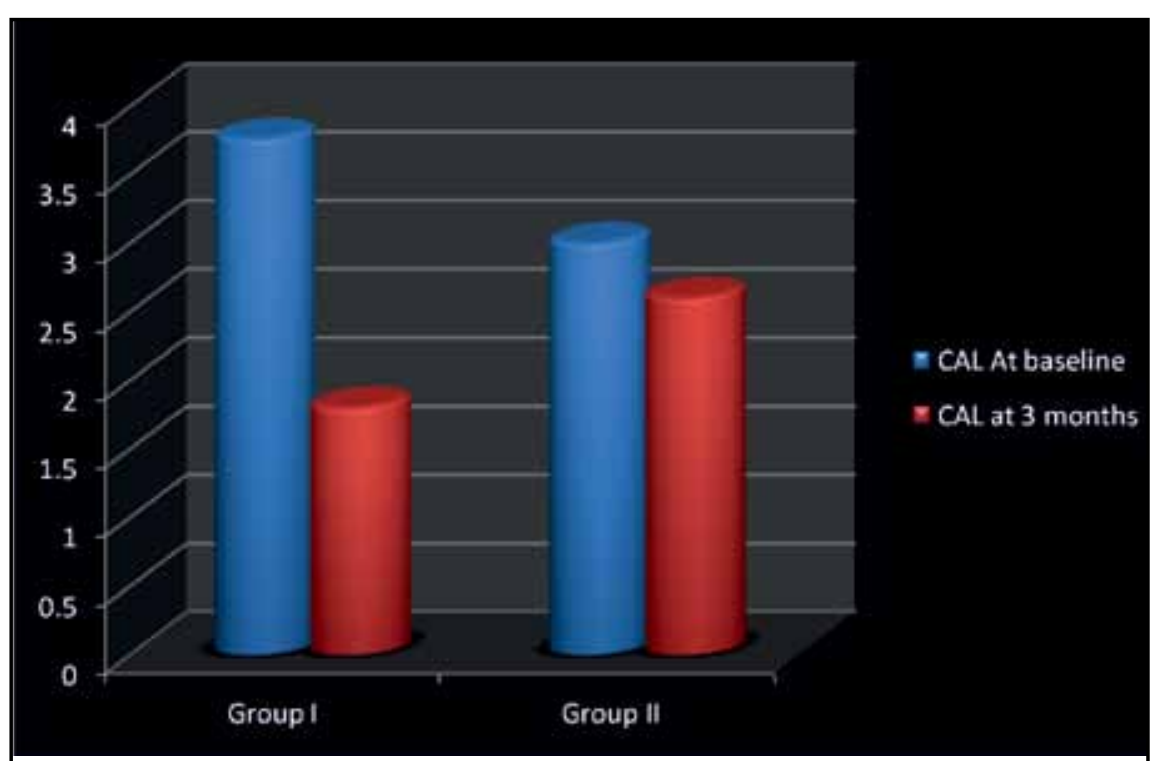

Figure 4: Comparison of clinical attachment level (cal) in the 2 groups at baseline and 3 months equate time for the antimicrobial effect to occur. Controlled release local drug delivery, in which the antimicrobial agent is available at therapeutic level for several days have been evaluated in several forms using different antimicrobial agents. Controlled drug delivery is designed to release drug slowly for more prolonged availability and sustained action (14).

There have been several agents used for local drug delivery. However, to the best of our knowledge, there are no studies comparing the efficacy of Tetracycline fibers (Periodontal AB Plus) and Povidone iodine as local drug delivery agents. Hence this study was taken up to understand and compare the efficacy of these agents.

30 patients with age ranging from 20-65years were selected for the study. Age is an important factor for periodontal disease and the prevalence of periodontal disease increases rapidly with age (15). This age range is in accordance with other studies (16).

The gingival index (GI) was used to assess the severity of gingivitis. It is sufficiently sensitive to distinguish between groups with mild and severe gingivitis. This is in accordance with previous studies (16).

A reduction in mean PPD, CAL and GI was found in both the groups. Other studies have also shown a decrease in PPD and GI and gain in CAL with the use of tetracycline fibers and povidone iodine (16-18).

The intragroup comparison between PPD, CAL and GI at baseline and 3 months using paired $t$ test showed a statistically significant difference in group I in relation to all parameters. This is in accordance with studies that have shown significant reduction in PPD and CAL with use of tetracycline fibers $(16,18)$.

In group II, the PPD and CAL did 


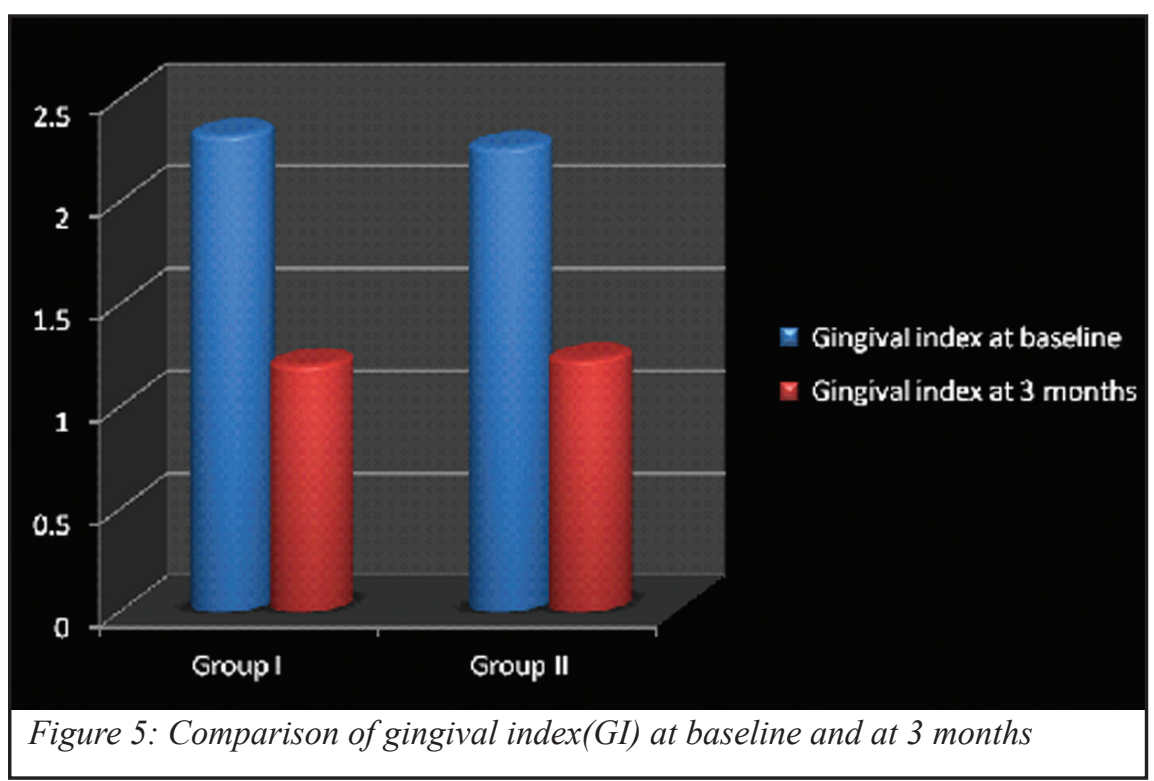

not show a statistically significant difference. This contradiction to the existing literature may be because of the variation in the concentration of povidone iodine used (17). However, the GI showed a statistically significant difference in group II.

Goodson et al (19), observed that tetracycline filled hollow fibers placed in the gingival sulcus have effects both on the microbiological and clinical aspects of periodontal disease. Lindhe et al(20) and Pavia et al(21) have also demonstrated the potential of tetracycline filled hollow fiber devices to change the composition of the subgingival flora and exert antibacterial activity and Rodrigues et al (22) observed that locally delivered tetracyclines had less chances of bacterial resistance.

In a comparative study by Thomas et al (23) which compared the effects of tetracycline fibers plus scaling and root planing versus scaling and root planing alone, it was observed that the use of fibers provided no significant advantage with regards to probing depth reduction or clinical attachment gain.

PVP-iodine has been used in various studies as an antiseptic adjunctive during nonsurgical periodontal therapy, but inconsistent results have been obtained. In a systematic review on the effectiveness of rinsing with povidone iodine (12), it was found that the two studies supporting an overall favorable effect of PVP-iodine use $(24,25)$ invesstudies with a less favorable outcome $(26,27)$ referred to multirooted teeth. One of the latter studies found a statistically significant additional benefit for PVP iodine in a subgroup with periodontal pocket depth $>5 \mathrm{~mm}$ for all re-evaluation time-points.(26)An additional benefit for this antiseptic was seen in another study that investigated the effect of PVP-iodine during scaling and root planing on single-rooted teeth (28).

The intergroup comparison of PPD and CAL at the end of 3 months, using unpaired $t$ test showed a statistically significant difference between the two groups. There was no statistically significant difference in GI between the two groups at the end of 3 months. To the best of our knowledge there are no studies comparing these two agents in local drug delivery. Hence a comparison with studies in literature was not possible.

The small sample size is a drawback of the study along with the fact that no microbiological analysis was done to tigated single-rooted teeth; two of the verify the changes in microbial composition. Longitudinal studies using larger sample size and better standardization and microbial analysis are required to arrive at a more conclusive interpretation.

\section{CONCLUSION}

Within the limitations of the study, it was seen that both Tetracycline fibers and Povidone iodine can improve periodontal disease status. Both Tetracycline Fibers and Povidone Iodine appear to have nearly comparable effects, with Tetracycline fibers displaying slightly superior effect in comparison to Povidone iodine. Further investigations will be required to resolve the controversies related to the local drug delivery systems such as induction of bacterial resistant strains, the efficacy of systemic versus local drug delivery and whether local drug delivery should function as an alternative or as an adjunct to conventional treatment. Long-term, randomized, controlled clinical trial will be needed to arrive at a definitive conclusion regarding the efficacy and supremacy of the local drug delivery systems used in the study and to apply the knowledge in clinical practice.

\section{REFERENCES}

1. PD Marsh. Host defences and microbial homeostasis: role of microbial interactions. J Dent Res 1989;68:1567-75.

2. AD Haffajee, SS Socransky. Microbial etiological agents of destructive periodontal disease. Periodontology 2000;1994;78-111.

3. JD Suomi, JD West, JJ Chang, BJ McClendon. The effect of controlled oral hygiene procedures on the progression of periodontal disease in adults: radiographic findings. J Periodontol 1971;42:562-64.

4. J Gordon, C Walker, I Lamster, T West, S Socransky, M Seiger. Efficacy of clindamycin hydrochloride in refractory periodontitis. 12-month results, J Periodontol 1985;56:75-80.

5. Mombelli AJ. Van Winkelhoff. The systemic use of antibiotics in periodontal therapy, in: N.P. Lang, T. Karring, J. Lindhe (Eds.). Proceedings of the Second European Workshop on Periodontology, Quintessence, London, 1997;pp38-77.

6. CM Bollen, M Quirynen. Microbiological response to mechanical treatment in 
combination with adjunctive therapy. A review of the literature. J Periodontol 1996;67:1143-58.

7. KS Kornman. Controlled release local delivery antimicrobials in periodontics. Prospects for the future. J Periodontol 1993;64:782-91.

8. I.G. Needleman. Controlled drug release in periodontics. A review of new therapies. Br Dent J 1991;170 :405-08.

9. U Noyan, S Yilmaz, B Kuru, T Kadir, O Acar, E Buget. A clinical and microbiological evaluation of systemic and local metronidazole delivery in adult periodontitis patients. $J$ Clin Periodontol 1997;24:158-65.

10. Aimetti M, Romano F, Torta I, Cirillo D, Caposio P, Romagnoli R. Debridement and local application of tetracycline-loaded fibres in the management of persistent periodontitis: results after 12 months. $J$ Clin Periodontol 2004;31(3):166-72.

11. Goodson JM, Cugini MA, Kent RL, et al. Multicenter evaluation of tetracycline therapy: Clinical response. J Periodontol Res 1991;26:371-75.

12. $P$ Sahrmann, MA. Puhan, T Attin, PR. Schmidlin. Systematic review on the effect of rinsing with povidone-iodine during nonsurgical periodontal therapy. J Periodont Res 2010;45:153-64.

13. Rams TE, Slots J. Local delivery of antimicrobial agents in the periodonta pocket. Periodontology 2000;1996;10: 139-59.

14. Gupta SC. Local drug delivery in Periodontics. Indian J Dent Sci
2010;2(1):32-34

15. Rose LF, Genco RJ, Mealy BL, Cohen WD. Periodontal Medicine. BC Decker Inc. 2000.

16. Shetty S, Shakir Q JA. The therapeutic evaluation of scaling and root Planing alone and with tetracycline (periodontal Plus ABTM) combination therapy, in patients with Chronic periodontitis -a clinical and microbiological study. Scientific journal. 2007;1

17. Kotsilkov K, Emilov D, Popova C. Subgingival irrigations with povidone iodine as adjunctive treatment of Chronic periodontitis. Journal of IMAB - Annual Proceeding (Scientific Papers) 2009, book 2,p 84-88.

18. Panwar M, Gupta SH. Local Drug Delivery with Tetracycline Fiber: An Alternative to Surgical Periodontal Therapy. MJAFI 2009;65:244-46.

19. Goodson JM, Hafazee A, Socransky SS. Periodontal therapy by local delivery of tetracycline. J Clin Periodontol 1979;6: 83.

20. Lindhe J, Heijl L, Goodson JM, Socransky SS. Local tetracycline delivery using hollow fiber devices in periodontal therapy. Journal of Clinical Periodontology 1979; 6:141-49.

21. Pavia M, Nobile CG, Angelillo IF. Meta analysis of local tetracycline in treating chronic periodontitis. J Periodontol 2003; 74: 916-32.

22. Rodrigues RM, Concalves C, Souto $R$. Antibiotic resistance profile of the subgingival microbiota following systemic and local tetracycline therapy. J Clin Periodontol 2004;31:420-27.

23. Thomas $G$ Wilson Jr, Mcguire MK, Greenstien G, Nunn M. Tetracycline fiber plus scaling and root planing versus scaling and root planing alone. Journal Periodontol 1998;25:1029-32.

24. Rosling B, Hellstrom MK, Ramberg $P$, Socransky SS, Lindhe J. The use of PVPiodine as an adjunct to non-surgical treatment of chronic periodontitis. J Clin Periodontol 2001;28:1023-31.

25. Forabosco A, Spinato S, Grandi T, Prini M. A comparative study between different techniques in non-surgical periodontal treatment. Minerva Stomatol 2006;55: 289-96.

26. Del Peloso Ribeiro E, Bittencourt S, Ambrosano GM, et al. Povidone-iodine used as an adjunct to non-surgical treatment of furcation involvements. $J$ Periodontol 2006;77:211-17.

27. Zanatta GM, Bittencourt S, Nociti FHJ, Sallum EA, Sallum AW, Casati MZ. Periodontal debridement with povidoneiodine in periodontal treatment: short term clinical and biochemical observations. J Periodontol 2006;77: 498-05.

28. Christersson LA, Rosling BG, Dunford RG, Wikesjo UM, Zambon JJ, Genco RJ. Monitoring of subgingival Bacteroides gingivalis and Actinobacillus actinomycetemcomitans in the management of advanced periodontitis. Adv Dent Res 1988;2:382-388. 